\title{
Good Worker Health and Hygiene Practices: Evaluation and Importance in GAPs and GMPs ${ }^{1}$
}

\author{
Melissa Holmes-Pearce, Mark Ritenour, Amy Simonne, Jeff Brecht, Steve Sargent, and Keith \\ Schneider ${ }^{2}$
}

\section{Overview}

With increased consumption of fresh produce, the number of foodborne illnesses associated with fresh produce has also increased. Young children, the elderly, and people with immuno-compromising conditions such as HIV, AIDS, and cancer run even greater risk of serious illness or death related to contaminated foods. Therefore, it is now more important than ever that everyone involved in handling food uses recommended sanitation practices. Regardless if one works in the field, a packinghouse, a warehouse, on the loading dock, at a grocery store, or in a restaurant, good practices that assure food safety start at home and continue into the workplace. Always remember that the food products you handle MUST be safe to consume when they leave your care; your job depends on it.

Because of the potential risks regarding fresh produce consumption, the Food and Drug Administration (FDA) and the United States Department of Agriculture (USDA) issued the
"Guide to Minimize Microbial Food Safety Hazards for Fresh Fruits and Vegetables" (http://www.foodsafety.gov/ dms/prodguid.html)), which defines Good Agricultural Practices (GAPs) for fresh fruit and vegetable handling. Though the principles and practices discussed in this guide have been widely adopted, they remain a guidance and do not constitute regulation. These good management practices apply to general practices, which decrease microbial food safety hazards during growing, harvesting, sorting, packing, storage, and transportation operations. In addition, Good Manufacturing Practices (GMPs) (21CFR110) which more specifically cover sorting, packing, storage, and transportation associated with packing or processing facilities should also be followed.

Because safe food is an absolute requirement in the eyes of consumers and an entitlement in the eyes of regulators, any case of food contamination can devastate an industry. Even fresh produce that is only mentioned as a potential cause can experience drastic reductions in sales because of the public's perceived

1. This document is FCS8766, one of a series of the Department of Family, Youth and Community Sciences, Florida Cooperative Extension Service, Institute of Food and Agricultural Sciences, University of Florida, Gainesville, FL 32611. Publication: December 2004. Please visit the EDIS Web site at http://edis.ifas.ufl.edu

2. Melissa Holmes-Pearce, student; Amy Simonne, PhD, assistant professor, Family, Youth and Community Sciences; Jeff Brecht, PhD, professor, Horticultural Sciences; Steve Sargent, PhD, professor, Horticultural Sciences; Keith Schneider, PhD, assistant professor, Food Science and Human Nutrition; University of Florida, Gainesville, 32611. Mark Ritenour, PhD, associate professor, Indian River REC, Fort Pierce, 34945. Reviewed by Ron H. Schmidt, PhD, professor, Food Science and Human Nutrition, University of Florida, Gainesville, FL, 32611.

The Institute of Food and Agricultural Sciences (IFAS) is an Equal Opportunity Institution authorized to provide research, educational information and other services only to individuals and institutions that function with non-discrimination with respect to race, creed, color, religion, age, disability, sex, sexual orientation, marital status, national origin, political opinions or affiliations. U.S. Department of Agriculture, Cooperative Extension Service, University of Florida, IFAS, Florida A. \& M. University Cooperative Extension Program, and Boards of County Commissioners Cooperating. Larry Arrington, Dean 
loss in confidence with the safety of the product. In response to customers' concerns and issues of liability, most buyers now require suppliers and handlers of fresh produce to submit to independent, third party audits and inspections to assure adoption and compliance with GAPs and GMPs.

\section{The Importance of Good Worker Health and Hygiene in GAPs and GMPs}

Good worker health and hygiene is critical to preventing foodborne illness. It is so critical that the Centers for Disease Control and Prevention (CDC) point to poor personal hygiene as being among the most common causes of foodborne illness.

Maintaining good worker health and hygiene requires a sanitary facility and workers who are healthy, practice personal cleanliness, and who refrain from personal behaviors known to spread disease.

Common factors involved in the spread of human infectious organisms include:

- Sick employees

- Employees with open cuts and scrapes

- Employees who touch their faces and mouths with their hands

- Employees who do not wash their hands after using the restroom

- Unwashed hands or contaminated gloves

- Unwashed and poorly sanitized food handling areas, and soiled clothing

\section{Evaluating Worker Hygiene Practices}

Complete and consistent documentation is critical for any food safety program. Regular inspection, documentation, and evaluation of the entire operation and of individual systems within the operation offer owners and managers the opportunity to better monitor processes in the plant, quickly identify and correct potential problems, and reduce the overall potential for contamination. Furthermore, in the event of foodborne illness, good records can quickly satisfy investigators and allow them to move away from your company and onto other potential offending companies.

Check-off sheets represent an easy way to evaluate the overall completeness of an operation's food safety program. These may cover every conceivable part of a food safety program and many companies have developed a variety of check-off sheets to evaluate a broad range of food-handling operations. Table 1 offers sample criteria one can use when evaluating worker health and hygiene practices within a fresh fruit and/or vegetable operation.

Standard Operating Procedures (SOPS) and Sanitation Standard Operating Procedures (SSOPs) may then be written describing specific and detailed daily procedures to prevent food contamination for each item identified on the check-off sheet. Daily sanitation checklists are also useful to record regular inspection of restrooms, hand-washing stations, etc. (see Table 2 for an example). Even if no action is needed, a record of the inspection must be noted.

Good hand washing practices must be performed after using restrooms, smoking, handling rotten fruit, etc.; before touching clean fruits and vegetables, applying new gloves, and preparing and consuming food, etc. on the worksite. The correct way to wash hands is to remove all jewelry, use warm soapy water, and lather hands up to elbows for 20 seconds. Make sure to wash the back of hands and scrub between and under fingernails. Then rinse hands under water and dry with disposable paper towels.

\section{Conclusion}

The world continues to change, with different countries having different standards for food safety. It must be effectively communicated to everyone involved with the handling your product throughout the food production and distribution chain (from the farm to the table), that GAPs and GMPs are the responsibility of everyone. Practicing good worker health and hygiene will help enhance the safety of fresh fruits and vegetables and promote consumer demand for your product. 
Table 1. An example of a worker health and hygiene check-off sheet

\begin{tabular}{|c|c|c|}
\hline Training: Human Health \& Hygiene & $\begin{array}{c}\text { Documented Compliance } \\
\text { (Yes/No) }\end{array}$ & Comments \\
\hline \multicolumn{3}{|l|}{ All employees receive basic instruction in food safety. } \\
\hline \multicolumn{3}{|l|}{$\begin{array}{l}\text { Supervisors are trained to be familiar with the typical } \\
\text { signs and symptoms of infectious illnesses. }\end{array}$} \\
\hline \multicolumn{3}{|l|}{$\begin{array}{l}\text { All employees receive training in good personal } \\
\text { hygiene (including bathing, hand washing, teeth } \\
\text { brushing, wound care, etc.). }\end{array}$} \\
\hline \multicolumn{3}{|l|}{$\begin{array}{l}\text { The importance of good hygiene, and regular and } \\
\text { thorough hand washing are stressed on a consistent } \\
\text { basis. }\end{array}$} \\
\hline Practices: Human Health \& Hygiene & $\begin{array}{c}\text { Documented Compliance } \\
\text { (Yes/No) }\end{array}$ & Comments \\
\hline \multicolumn{3}{|l|}{$\begin{array}{l}\text { The company has a personnel policy in place to } \\
\text { prevent sick workers from handling fresh produce. }\end{array}$} \\
\hline \multicolumn{3}{|l|}{$\begin{array}{l}\text { All employees are observed daily for signs of illness or } \\
\text { injury. }\end{array}$} \\
\hline \multicolumn{3}{|l|}{$\begin{array}{l}\text { No employee with open wounds or showing signs of } \\
\text { illness handles fruit. }\end{array}$} \\
\hline \multicolumn{3}{|l|}{ Employees have easy access to potable water. } \\
\hline \multicolumn{3}{|l|}{$\begin{array}{l}\text { All personnel wash their hands in warm, soapy water } \\
\text { for } 20 \text { seconds before returning to work. }\end{array}$} \\
\hline \multicolumn{3}{|l|}{ Workers have nearby access to clean toilets. } \\
\hline \multicolumn{3}{|l|}{$\begin{array}{l}\text { Employees dispose of personals in restroom areas } \\
\text { only. }\end{array}$} \\
\hline \multicolumn{3}{|l|}{$\begin{array}{l}\text { Workers have nearby access to clean, well-stocked } \\
\text { hand washing stations. }\end{array}$} \\
\hline \multicolumn{3}{|l|}{$\begin{array}{l}\text { Employees smoke only in designated areas, well } \\
\text { separated from food and working areas. }\end{array}$} \\
\hline \multicolumn{3}{|l|}{$\begin{array}{l}\text { Food is stored and consumed in designated eating } \\
\text { areas only. }\end{array}$} \\
\hline \multicolumn{3}{|l|}{ Working areas are kept clean at all times. } \\
\hline \multicolumn{3}{|l|}{ Pets are not allowed on facility premises. } \\
\hline $\begin{array}{l}\text { The company has a policy to quickly identify and } \\
\text { destroy products that contact blood or other bodily } \\
\text { fluids. }\end{array}$ & & \\
\hline
\end{tabular}

Table 2. Example of a checklist for inspection, cleaning, and resupplying of a restroom facility

\begin{tabular}{|c|c|c|c|c|}
\hline & Date: & & & \\
\hline Restroom \# xxx & $\begin{array}{c}\text { 7:00 a.m. - } \\
\text { 10:00 } \\
\text { a.m. }\end{array}$ & $\begin{array}{l}\text { 10:00 a.m. - } \\
\text { 12:00 p.m. }\end{array}$ & $\begin{array}{l}\text { 12:00 p.m. - } \\
\text { 3:00 p.m. }\end{array}$ & $\begin{array}{l}\text { 3:00 p.m. - } \\
\text { 6:00 p.m. }\end{array}$ \\
\hline Sink and Toilets & $\begin{array}{l}\text { Cleaned \& } \\
\text { Sanitized }\end{array}$ & OK & OK & OK \\
\hline Floors & $\begin{array}{l}\text { Cleaned \& } \\
\text { Sanitized }\end{array}$ & OK & Swept & OK \\
\hline Soap & OK & $\mathrm{OK}$ & Re-filled & OK \\
\hline Towels & OK & OK & Re-filled & OK \\
\hline
\end{tabular}


For more information, visit the "Sanitation,

Food Safety \& Security" section of the University of

Florida's Postharvest Information website

(http://postharvest.ifas.ufl.edu). 